\title{
Rural and Remote Registered Nurses' Perceptions of Working Beyond Their Legislated Scope of Practice
}

\author{
Martha L.P. MacLeod, PhD, RN \\ Professor, and the Northern Health - \\ UNBC Knowledge Mobilization \\ Research Chair \\ School of Nursing, \\ University of Northern British Columbia \\ Prince George, BC
}

Norma J. Stewart, RN, PhD

Professor Emerita

College of Nursing, University of Saskatchewan Saskatoon, SK

Julie G. Kosteniuk, PhD Professional Research Associate Canadian Centre for Health and Safety in Agriculture University of Saskatchewan Saskatoon, SK

Kelly L. Penz, PhD, RN Assistant Professor College of Nursing, University of Saskatchewan, Regina Campus Regina, SK

Janna Olynick, MSc Research Associate School of Nursing, University of Northern British Columbia Prince George, BC

Chandima P. Karunanayake, PhD

Professional Research Associate Canadian Centre for Health and Safety in Agriculture University of Saskatchewan Saskatoon, SK
Kelley Kilpatrick, RN, PhD

Associate Professor

Susan E. French Chair in Nursing Research and Innovative Practice Ingram School of Nursing, McGill University

Montréal, QC

Judith C. Kulig, PhD, RN

Professor Emerita

Faculty of Health Sciences, University of Lethbridge Lethbridge, $A B$

Ruth Martin-Misener, NP, PhD Professor and Interim Director Dalhousie University School of Nursing Halifax, NS

Irene Koren, MSc, RN

Assistant Professor

School of Nursing, Laurentian University Sudbury, ON

Lela V. Zimmer, PhD, RN

Associate Professor

School of Nursing, University of Northern British Columbia Prince George, BC

Linda Van Pelt, MScN, NP-F

Assistant Professor

School of Nursing, University of Northern British Columbia Prince George, BC

Leana Garraway, MA

Research Associate

School of Nursing,

University of Northern British Columbia

Prince George, BC 


\begin{abstract}
Registered nurses (RNs) enact their scope of practice in everyday practice through the influences of client needs, the practice setting, employer requirements and policies and the nurse's own level of competence (Canadian Nurses Association 2015). A scope of practice is "dynamic and responsive to changing health needs, knowledge development and technological advances" (International Council of Nurses 2013). In Canada, RNs' scope of practice is set out through provincial and territorial legislation and provincial regulatory frameworks, which are broadly consistent, but vary across provinces (Schiller 2015). Provincial and territorial regulatory bodies articulate the RN scope through frameworks that include expected standards as well as, in some jurisdictions, limits and conditions upon practice (British Columbia College of Nursing Professionals 2018), and which are commonly referred to as a licensed or registered scope of practice. Rural and remote practice is starting to be explicitly acknowledged within nurses' legislated scopes of practice through the identification of certified practices for RNs in specific rural and remote practice settings, following approved education (British Columbia College of Nursing Professionals 2018).
\end{abstract}

In $\mathbf{2 0 1 5}, \mathbf{1 0} \%$ and $\mathbf{4 0 \%}$ of Registered Nurses (RNs) in Canada's provinces and territories, respectively, worked in rural locations (MacLeod et al. 2017a). These RNs provided healthcare to the $17 \%$ of Canada's population who live in rural locations in the provinces and $52 \%$ of those who live in rural locations in the territories (Canadian Institute for Health Information 2017). Rural and remote nurses' practice is generalist and complex (Knight et al.2016) with high levels of autonomy (Birks et al. 2016; Kulig et al. 2013) and requires well-honed problem-solving skills (Kulig et al. 2013). This broad scope of practice is because of geographic isolation, low population density, few resources, limited support and the requirement to address both workplace and community demands (Fowler et al. 2018; MacLeod et al. 2008; Martin-Misener et al. 2008). Critical decisions are often made with limited support from other healthcare professionals, which may pressure nurses to act beyond their licensed scope (Hunsberger et al. 2009). Although it is anticipated that nurses will work within their scope of practice, it is acknowledged that nurses regularly work within, below and beyond their legislated scope of practice (Feringa et al. 2018).

Despite increasing attention to the rural and remote nursing workforce, nurses' scope of practice in these settings has remained largely unexamined. In the Nursing Practice in Rural and Remote Canada II (RRNII) study, MacLeod et al. (2017a, 2017b) elicited nurses' perceptions of their scope of practice. One question asked nurses to identify whether they perceived their current role to be below, within or beyond their registered/licensed scope of practice. The purpose of this article is to explore predictors of RNs' perceptions of working beyond their legislated scope of practice in rural and remote settings. 


\section{Methods}

\section{Design}

The cross-sectional survey of Nursing Practice in Rural and Remote Canada (RRNII) (MacLeod et al. 2017b) replicated and extended the first Nature of Nursing Practice in Rural and Remote Canada (RRNI) cross-sectional survey (Stewart et al. 2005). The present analysis draws on RRNII data using a scope of practice question that was not included in the RRNI survey. In both the RRNI and RRNII surveys, rural was defined as populations outside the commuting zones of communities with a population of 10,000 or more (du Plessis et al. 2001). Remote respondents were not specifically identified. We have used the term "rural and remote" based on findings from the RRNI survey (Stewart et al. 2005) in which RNs' definitions of rural and remote workplaces were more similar than different (Kulig et al. 2008). The RRNII survey, in French and English, was mailed in 20142015 to regulated nurses (nurse practitioners, RNs, licensed or registered practical nurses and registered psychiatric nurses) using the Dillman method of tailored design and repeated follow-up (Dillman et al. 2014).

\section{Study sample}

The systematically stratified sample included 10,072 rural regulated nurses in Canada's 10 provinces and all regulated nurses in the three territories. Provincial/ territorial nursing regulatory colleges and associations assisted with obtaining the sample. A total of 9,622 nurses were eligible and 450 were ineligible (e.g., worked urban, address incorrect). The overall response rate was $40 \%(3,822 / 9,622)$. Of 5,269 eligible RNs, 2,082 returned completed surveys (40\% response rate). The $\mathrm{RN}$ respondents $(n=2,082)$ were representative of rural Canada RNs as a whole, at a $99 \%$ confidence level with a $2.0 \%$ margin of error (MacLeod et al. 2017b). The present analysis includes RNs who were managers, staff nurses and clinical nurse specialists and excludes educators, researchers and consultants/analysts. It was conducted using a subsample of $1,754 \mathrm{RNs}$ who responded to a survey question indicating that they think of their role as either within $(n=1,572)$ or beyond ( $n=182)$ their registered/licensed scope of practice. The RNs who perceived their role as below their registered/licensed scope of practice $(n=105)$ were excluded from the present analysis based on the number and the assumptions that determinants of working below scope of practice would differ and that the policy and practice implications of working beyond scope were greater.

\section{Variables included in the analysis}

The scope of practice survey item was recoded into "working within and working beyond" and included as the main outcome (SOP-Beyond) for this multivariable analysis. This variable measured nurses' perception of their current scope of practice as beyond or within their registered/licensed scope. Sixteen independent variables included individual, community and workplace factors. 
The five individual variables (demographic and employment) were gender (male/ female), age (five-year categories from under 30 to $60+$ ), highest attained nursing education (diploma, bachelor's degree or masters/doctorate), province or territory of primary nursing employment and primary place of employment (primary care, community-based healthcare, hospital, nursing home/long-term care and other).

Four work community variables related to rurality and remoteness included the number of rural and/or remote communities worked in for three months or longer (four categories from one to three months to $10+$ months), population of primary work community (three categories from $\leq 999$ to $>10,000$ ), accessibility only by plane (yes/no) and distance $(\mathrm{km})$ of primary work community from closest advanced referral centre.

Finally, seven workplace variables were included: respondents' use of online information sources (four-point Likert item from rarely to daily); requirement to be on call (yes/no); burnout (seven-point Likert item "I feel burned out from my work" from never to always); three subscales from the Job Resources in Nursing (JRIN) Scale (Penz et al. 2019) measuring practice resources related to staffing and time, collegial support and training, professional development and continuing education; and one subscale from the Job Demands in Nursing (JDIN) Scale (Penz et al. 2019) measuring the demands related to preparedness/scope of practice. Each of the above four-item subscales were measured on a five-point Likert scale (strongly disagree to strongly agree).

\section{Analysis}

Data were analyzed in IBM SPSS Statistics 24. A total of 51 variables were selected as possible predictors of SOP-Beyond through considering clinical relevance, current literature (i.e., gender, age and education) and conceptual/methodological relevance. Bivariate analyses were conducted using chi-square for frequency data and $t$-tests or ANOVA for continuous data. Sixteen variables significantly associated $(p<0.20)$ with SOP-Beyond were selected for inclusion in logistic regression analysis. When potential predictors had a Pearson correlation above 0.5 , only one variable was kept unless there was a theoretical reason to keep both. Logistic regression was conducted using the "enter" method and the significance of each odds ratio assessed $(p<0.05)$.

\section{Results}

Overall, $84.6 \%$ of rural and remote RNs perceived their practice to be within their legislated scope of practice, with more reporting working beyond $(9.8 \%)$ than below (5.6\%) their scope. Table 1 (available online at longwoods.com/ content/25851) shows the frequencies, means, unadjusted odds ratios and 
95\% confidence intervals for the 16 variables significantly associated with SOP-Beyond $(p<0.20)$. The adjusted odds ratios for each of the nine independent variables and the outcome of SOP-Beyond, while controlling for the effects of all other variables within the final model, are also reported in Table 1.

Four demographic and employment variables were predictive of working beyond scope. Male RNs were nearly three times as likely to identify working beyond scope compared to female RNs. RNs aged 34 years and under were over six times as likely to identify working beyond scope compared to those 60 years and over. RNs in four provinces (Newfoundland, New Brunswick, Québec and Manitoba) were over four times as likely to identify working beyond scope compared to RNs in Ontario. RNs working in primary care settings were over twice as likely to identify working beyond scope compared to RNs in a hospital setting.

Two of the work community variables related to rurality and remoteness predicted perceptions of working beyond scope. RNs working in a fly-in community were over twice as likely to identify working beyond scope compared to RNs whose primary work community was more accessible. RNs who worked 1,000+ km from an advanced referral centre were over four times as likely to identify working beyond scope, compared to RNs who worked 0-99 km from such a centre. Finally, three workplace variables were predictive. As resources related to staffing and time decreased, RNs were more likely to perceive that they were working beyond scope. Moreover, the higher the job demands related to preparedness for the scope of practice (i.e., acquiring the necessary knowledge to do the work), the more likely RNs considered themselves to work beyond scope. Finally, RNs who were required to be on call were over twice as likely to identify working beyond scope compared to RNs not required to be on call.

\section{Discussion}

In the call to optimize health professionals' scopes of practice (Nelson et al. 2014), there is an assumption that many RNs are working below scope. This was not found in our study of rural and remote nurses, where close to $85 \%$ noted that they practiced within and almost 10\% reported working beyond their legislated scope. While working below scope has been related to inefficiencies and dissatisfaction (e.g., Oelke et al. 2008), working beyond scope has been linked to compromised practice and nursing stress (Feringa et al. 2018).

In remote geographic areas where there is a lack of services, a lack of on-site physicians, isolation, inclement weather and challenges in transporting patients, RNs often are required to take on greater decision-making and primary care responsibilities (Martin-Misener et al. 2008). At the same time, in those settings, healthcare professionals may experience greater autonomy and flexibility in how the 
boundaries of their practice "are interpreted and applied" (Ford 2016: 244). There may be a lack of formal or informal articulation of scope of practice through policies or protocols (Birks et al. 2016), and as a result, some RNs may consider themselves to be working beyond their legislated scope of practice, whereas others may perceive themselves to be working within scope.

Although we have not found studies that can be related specifically to our findings regarding men and younger nurses, men overall may experience more societal pressure to take risks (Figner and Weber 2011) and younger nurses may expect more concrete formal supports in workplaces (Francis and Mills 2011). These support mechanisms, such as mentoring and clinical supervision, are more difficult to implement in rural practice settings (Lea and Cruickshank 2015). In addition, younger nurses, in contrast to those over 60 , may have experienced more explicit integration of knowledge of scopes of practice, practice standards and relevant legislation within their nursing education programs (British Columbia College of Nursing Professionals 2018; Schiller 2015) and so may be more attuned to the stated boundaries of their practice.

RNs working in primary care, particularly in fly-in communities that are distant from advanced referral centres, are frequently required to be flexible in their practice. Although flexible scopes of practice for rural/remote clinicians are considered positively, they place undue stress on practitioners when they are compensating for staff shortages or operating beyond their skill level (McNeil et al. 2015). The higher demands related to gaining the necessary knowledge, skills and overall preparedness for practice in remote settings are considerable (Martin-Misener et al. 2008). For example, a new nurse working on call may be required to accompany a critically ill patient during transport as the most qualified professional. In these situations, RNs may feel they are working beyond scope. The job resources and demands in such primary care and remote settings, coupled with a necessity to be on call, are not easily rectified. However, workplace modifications could be targeted to ensure a supportive leadership structure and processes, a supportive staff mix, sufficient staff and facilitative technology that can help to alleviate RNs' sense of isolation and individual responsibility for their own preparedness (Lea and Cruickshank 2015).

RNs working beyond scope were also more likely to be working in the provinces of Newfoundland, New Brunswick, Québec and Manitoba than in Ontario. This finding cannot be readily explained, as Ontario also has a number of remote, fly-in communities where RNs work in primary care settings. Differing availability of physicians and supportive infrastructures such as telehealth may be contributing factors. In rural and remote settings, when no physicians are on site, nurses will perform the necessary interventions to support patients' survival. As well, 
within changing regional and provincial health systems and their evolving role in primary care, RNs may perceive some responsibilities, such as leading screening clinics, to be beyond their scope when such roles are within scope. To address rural and remote practice needs, some provincial regulators have begun to address support requirements within a regulatory framework. An example is British Columbia, which has initiated certified practice designations designed to support nurses in undertaking certain restricted activities through RN First Call and Remote Nursing certifications (British Columbia College of Nursing Professionals 2018).

Given that the RN scope of practice varies across the country, nurses recruited from other provinces may assume that the scope of practice in one province is the same as in another province or territory (Schiller 2015). Such situations may contribute to RNs perceiving themselves to be working beyond scope when they are working within scope. Nurses may also perceive their work to be beyond their legislated scope of practice when changing practice expectations have accompanied workplace restructuring or redesign, such as in New Brunswick (Rhéaume et al. 2015). Within such a changing context, where tasks are shifted to others on the team and the scope of practice evolves, some nurses may perceive themselves to be working beyond their scope, even though their actual work responsibilities remain within their legislated scope of practice.

Our findings support Knight et al.'s (2016) contention that the ways in which rural RNs are embedded within their community and geographical contexts lends additional complexity to rural RNs' scope of practice. These "complex contextual factors ... push rural nurses to work outside organisational and professional boundaries and processes" (Knight et al. 2016: 1759). This complexity was echoed by open-ended data from an RN in the RRNII study:

Rural nursing requires nurses to stretch themselves right out to the far reaches of their scope of practice, as many have to work independently and still stay within the limitations of that scope and also the limited resources of rural areas, while still providing quality care to each client.

The study findings prompt a reconsideration of how an $\mathrm{RN}$ scope of practice might best be depicted within rural and remote contexts. A model of enacted SOP proposed by Déry et al. (2015) takes into consideration many of the jobrelated factors and personal characteristics included in this study but lacks the "fluid set of parameters" (Birks et al. 2016: 539) required for the rural and remote geographical context. Future studies should explore the ways in which rural and remote communities shape nurses' enacted scope of practice. 


\section{Limitations}

The survey questions relate to what nurses perceive to be their responsibilities rather than what may or may not be within their legislated scopes of practice. It was also not possible to ascertain RNs' enacted scopes of practice.

\section{Conclusion}

A nuanced understanding of rural and remote nurses' scopes of practice is needed as new practice settings and roles for RNs evolve in Canada's ever-changing healthcare system. To foster optimal scopes of practice for rural and remote nurses, the lines of dialogue among nurses, their employers and nursing regulators need to be opened. Insights into nurses' perceptions of their scopes of practice may contribute to opening that dialogue so that ongoing personal, workplace and community supports at the micro, meso and macro levels (Nelson et al. 2014) can be developed and implemented.

\section{Acknowledgement}

This article stems from the study: "Nursing Practice in Rural and Remote Canada II," led by MacLeod, M., Stewart, N., and Kulig, J (http://ruralnursing.unbc.ca). We acknowledge the funding from the Canadian Institutes of Health Research and the other in-kind funding. We thank the Advisory Team led by Penny Anguish of Northern Health, and nurses who responded to the survey. We also thank Steinunn Jónatansdóttir for her contributions.

Correspondence may be directed to: Martha MacLeod, School of Nursing, University of Northern British Columbia, 3333 University Way, Prince George, BC V2N 4Z9; email: martha.macleod@unbc.ca

\section{References}

Birks, M., J. Davis, J. Smithson and R. Cant. 2016. "Registered Nurse Scope of Practice in Australia: An Integrative Review of the Literature." Contemporary Nurse 52(5): 522-543. doi: 10.1080/10376178.2016.1238773.

British Columbia College of Nursing Professionals (BCCNP). 2018. RN Scope of Practice. Retrieved March 31, 2019. <https://www.bccnp.ca/Standards/RN_NP/RNScopePractice/Pages/Default.aspx>.

Canadian Nurses Association (CNA). 2015. Framework for the Practice of Registered Nurses in Canada. Retrieved March 31, 2019. <https://cna-aiic.ca/en/nursing-practice/the-practice-ofnursing $>$.

Canadian Institute for Health Information [CIHI]. 2017. Regulated Nurses, 2016: Canada and Jurisdictional Highlights. Retrieved March 31, 2019. < https://www.cihi.ca/sites/default/files/ document/regulated-nurses-2016-highlights_en-web.pdf $>$.

Déry, J., D. D’Amour, R. Blais and S.P. Clarke. 2015. "Influences on and Outcomes of Enacted Scope of Nursing Practice: A New Model.” Advances in Nursing Science 38(2): 136-143. doi: 10.1097/ ANS.0000000000000071.

Dillman, D.A., J.D. Smyth and L.M. Christian. 2014. Internet, Phone, Mail and Mixed-Mode Surveys: The Tailored Design Method, 4th Edition. Hoboken, NJ: Wiley \& Sons Inc. 
du Plessis V., R. Beshiri, R.D. Bollman and H. Clemenson. 2001. Rural and Small Town Canada Analysis Bulletin, Definitions of Rural. Retrieved March 31, 2019. <http://www.statcan>.

Feringa, M. M., H. C. De Swardt and Y. Havenga. 2018. “Registered Nurses’ Knowledge, Attitude, Practice and Regulation Regarding their Scope of Practice: A Literature Review." International Journal of Africa Nursing Sciences 8: 87-97. doi: https://doi.org/10.1016/j.ijans.2018.04.001.

Figner, B. and E. U. Weber. 2011. "Who Takes Risks When and Why? Determinants of Risk Taking." Current Directions in Psychological Science 20(4): 211-216. DOI: 10.1177/0963721411415790.

Ford, D. 2016. "Four Persistent Rural Healthcare Challenges." Healthcare Management Forum 29(6): 243-246. doi: 10.1177/0840470416658903.

Fowler, A. C., D. Twigg, E. Jacob and B. Nattabi. 2018. "An Integrative Review of Rural and Remote Graduate Programs and Experiences of Nursing Graduates." Journal of Clinical Nursing 27:e753-66. doi: 10.1111 /jocn.14211.

Francis, K. L. and J. E. Mills. 2011. "Sustaining and Growing the Rural Nursing and Midwifery Workforce: Understanding the Issues and Isolating Directions for the Future." Collegian 18(2): 55-60. doi:10.1016/j.colegn.2010.08.003.

Hunsberger, M., A. Baumann, J. Blythe and M. Crea. 2009. "Sustaining the Rural Workforce: Nursing Perspectives on Worklife Challenges." Journal of Rural Health 25(1): 17-25. doi: 10.1111/j.17480361.2009.00194.x.

International Council of Nurses (ICN). 2013. Scope of Nursing Practice: Position Statement. Retrieved March 31, 2019. <https://www.icn.ch/nursing-policy/position-statements >.

Knight, K., A. Kenny and R. Endacott. 2016. “From Expert Generalists to Ambiguity Masters: Using Ambiguity Tolerance Theory to Redefine the Practice of Rural Nurses." Journal of Clinical Nursing 25: 1757-1765. doi: 10.1111/jocn.13196.

Kulig, J. C., M. E. Andrews, N. L. Stewart, R. Pitblado, M. P. MacLeod, D. Bentham, D. Bentham, C. D’Arcy, D. Morgan, D. Forbes, G. Remus and B. Smith. 2008. "How do Registered Nurses Define Rurality?" The Australian Journal of Rural Health 16(1): 28-32. doi.org/10.1111/j.14401584.2007.00947.x.

Kulig, J., K. Kilpatrick, P. Moffitt and L. Zimmer. 2013. Rural and Remote Nursing Practice: An Updated Documentary Analysis. Lethbridge, AB: University of Lethbridge. RRN2-02. Retrieved March 31, 2019. <http://www.unbc.ca/rural-nursing/en/publications.>

Lea, J. and M. T. Cruickshank. 2015. "Supporting New Graduate Nurses Making the Transition to Rural Nursing Practice: Views from Experienced Rural Nurses." Journal of Clinical Nursing 24(1920): 2826-2834. DOI: 10.1111/jocn.12890.

MacLeod, M. L. P., R. Martin-Misener, K. Banks, A. M. Morton, C. Vogt and D. Bentham. 2008. “I'm a Different Kind of Nurse': Advice from Nurses in Rural and Remote Canada." Canadian Journal of Nursing Leadership 21(3): 40-53. doi:10.12927/cjnl.2008.20060.

MacLeod, M., N. Stewart, J. Kulig, J. Olynick, S. Jónatansdóttir and J. Kosteniuk. 2017a. Registered Nurse Survey Final Report: Nursing Practice in Rural and Remote Canada. Prince George, BC: Nursing Practice in Rural and Remote Canada II. RRN2-04-01.1. Retrieved March 31, 2019. $<$ http://www.unbc.ca/rural-nursing/en/publications $>$.

MacLeod, M. L. P., N. J. Stewart, J. C. Kulig, P. Anguish, M. E Andrews, D. Banner, L. Garraway, N. Hanlon, C. Karunanayake, K. Kilpatrick, I. Koren, J. Kosteniuk, R. Martin-Misener, N. Mix, P. Moffitt, J. Olynick, K. Penz, L. Sluggett, L. Van Pelt, E. Wilson and L. Zimmer. 2017b. "Nurses Who Work in Rural and Remote Communities in Canada: A National Survey." Human Resources for Health 15(34). doi:10.1186/s12960-017-0209-0.

Martin-Misener, R., M.L.P. MacLeod, K. Banks, A.M. Morton, C. Vogt and D. Bentham. 2008. "There's Rural and Then There's Rural: Advice from Nurses Providing Primary Healthcare in Northern Remote Communities." Canadian Journal of Nursing Leadership 21(3): 54-63. doi:10.12927/cjnl.2008.20062. 
McNeil, K., R. Mitchell and V. Parker. 2015. “The Paradoxical Effects of Workforce Shortages on Rural Interprofessional Practice." Scandinavian Journal of Caring Science 29: 73-82. doi:10.1111/ scs.12129.

Nelson, S., J. Turnbull, L. Bainbridge, T. Caulfield, G. Hudon, D. Kendel, D. Mowat, L. Nasmith, B. Postl, J. Shamian and I. Sketris. 2014. Optimizing Scopes of Practice: New Models for a New Health Care System. Ottawa, ON: Canadian Academy of Health Sciences.

Oelke, N. D., D. White, J. Besner, D. Doran, L. McGillis Hall and P. Giovannetti. 2008. “Nursing Workforce Utilization: An Examination of Facilitators and Barriers on Scope of Practice." Canadian Journal of Nursing Leadership 21(1): 58-71. doi:10.12927/cjnl.2008.19691.

Penz, K., J. G. Kosteniuk, N. J. Stewart, M. L. P. MacLeod, J. C. Kulig, C. P. Karunanayake and K. Kilpatrick. 2019. "Development and Psychometric Evaluation of the Job Demands in Nursing (JDIN) Scale and Job Resources in Nursing (JRIN) Scale: Results from a National Study." Nursing Open 6: 348-366. DOI: 10.1002/nop2.215

Rhéaume, A., S. Dionne, D. Gaudet, M. Allain, E. Belliveau, L. Boudreau and L. Brown. 2015. “The Changing Boundaries of Nursing: A Qualitative Study of the Transition to a New Nursing Care Delivery Model.” Journal of Clinical Nursing 24: 2529-2537. doi:10.1111/jocn.12846.

Schiller, C. J. 2015. "Self-regulation of the Nursing Profession: Focus on Four Canadian Provinces." Journal of Nursing Education and Practice 5(1): 95-106. doi: 10.5430/jnep.v5n1p95.

Stewart, N. J., C. D’Arcy, J.R. Pitblado, D. G. Morgan, D. Forbes, G. Remus, B. Smith, M. E. Andrews, J. Kosteniuk, JC. Kulig and M. L. MacLeod. 2005. "A Profile of Registered Nurses in Rural and Remote Canada." Canadian Journal of Nursing Research 37(1):122-145. doi:10.12927/ cjnl.2008.19690. 